\title{
Prevalence and factors affecting work-related injury among workers engaged in Small and Medium-Scale Industries in Gondar wereda, north Gondar zone, Amhara Regional State, Ethiopia
}

\author{
Takele Tadesse ${ }^{1}$, Abera Kumie ${ }^{2}$
}

\begin{abstract}
Background: In developing countries including Ethiopia, the risk of having work-related injury is 10 to 20 times higher than that of developed countries.

Objective: To asses the magnitude and factors affecting work-related injury among small and medium-scale industrial workers in North Gondar Zone, Ethiopia.

Methods: Institution-based cross-sectional comparative study was conducted from November to December, 2004 in Gondar Wereda. A total of 962 employed workers in small and medium-scale industries were selected randomly. Trained data collectors administered a pre-tested and standardized questionnaire. Physical examination and record review were done to ascertain self- reported injuries. Data were entered and cleaned using EPI INFO version 6.04 a statistical soft ware. SPSS window version 11.0 was also employed for descriptive and logistics regression analysis.

Results: The annual and two weeks prevalence rate of work-related injury was respectively 335 and 120 per 1000 exposed workers. Out of the total work-related injuries, 114 (35.5\%) and 208 (32.4\%) occurred among small and medium-scale industrial workers, respectively. The prevalence and severity of annual rate of injury was not associated with the type of industry. The most significant contributing factors for work-related injuries in such small and medium industries were service duration of 5 years or less in the present job [AOR: 1.53, $95 \%$ CI: (1.12-2.08)], working 48 hours or less per week [AOR: 0.68, 95 \% CI: $(0.49,0.94)$ ], workplace supervision [AOR: 0.61, $95 \%$ CI: $(0.45,0.83)]$, sleep disorder [AOR: 1.49, 95 \% CI: $(1.04,2.14)$ ] and job satisfaction [OR: 0.59, $95 \%$ CI: $(0.43,0.83)]$. Job categories related to mechanic and welding also represented to be factors positively affecting injury: [AOR: 2.09, $95 \%$ CI: (1.31, 3.33)], and [AOR: 3.23, $95 \%$ CI: $(1.98,5.28)]$, respectively. The above-mentioned factors made a difference in the outcome of injury by the type of industries. Hours worked per week, work place supervision and job satisfaction acted as protective in medium-scale industry, while being a mechanic, welder and sleeping disorder acted as a risk factor for the same industry.

Conclusion and Recommendation: Increased rate of work related injury was observed when compared with similar studies done elsewhere. Preventive measures concerning functional occupational health and safety programs are essential to safeguard the health and safety condition of workforce in small and medium scale industries. [Ethiop.J.Health Dev. 2007;21(1):25-34]
\end{abstract}

\section{Introduction}

Work-related injuries present a major public health problem resulting in serious social and economic consequences that could be prevented if appropriate measures are taken (1-3). Annually, throughout the world, an estimated number of 271 million people suffer with work-related injuries, and 2 million die as a consequence of these injuries. The estimated economic loss caused by work-related injuries and disease was equivalent to $4 \%$ of the world's gross national product (4). The impact is 10 to 20 times higher in developing counties, where the greatest concentration of the world's workforce is located (5). Moreover, the majority of the world's workforce does not have access to occupational health services. Only 5 to 10 percent of workforce in developing countries and 20 to 50 percent of workforce in developed countries have access to some kind of occupational health services (6). Small and medium-scale industries employed about $80 \%$ of the workforce and contribute over $90 \%$ of all industries in developing countries. Workers in these industries are at greater risk of work-related injuries, chronic illness, stress, and disability or death because of low educational and literacy rates, unfamiliarity with work process and exposures, and inadequate training (6-8).

According to a study conducted among 268 smaller industrial workers in Norway, injury rate of 317 per 1000 exposed workers was observed in the one-year period (9). Study carried out in Thailand in 2001 also reported that there were 189,621 cases of occupational injuries. Of this number, 607 were deaths, 20 cases of disability, and 48,078 cases of over 3 days lost from work (10). Results

\footnotetext{
${ }^{1}$ Department of Environmental and Occupational Health, College of Medicine and Health Sciences, University of Gondar, Email:takele tadesse@yahoo.com;Tel: 0918-773317; 2Department of Community Health, Faculty of Medicine, Addis Ababa University; Email: aberakumie2@yahoo.com; Fax:+251-15517701; Tel: 011-5157701; 0911882912
} 
from United States (US) study showed rate of 75 per 1000 exposed workers per year (11).

Studies that are available on industrial injuries in Africa indicated that work-related injuries appeared with greater frequency and severity. The injury rate among smallscale industrial workers in Zimbabwe was 131 per 1000 exposed workers per year (12)). The injury rate in Nigerian factories was 22 per 1000 exposed workers per year (13).

In Ethiopia, very limited attempts had been made to identify work-related injuries and their determinants even among large industrial workers. In a study among 3,100 textile factory workers in Addis Ababa reported an incidence rate of 200 injuries per 1000 exposed workers per year (15). The injury rate among 4,462 industrial workers in Addis Ababa was 80 pre 1000 exposed workers per year (14). Reports from Department of Environmental Health of Ministry of Health in the country indicated that among 16,610 large-scale industrial workers in Addis Ababa, a prevalence rate of 723 injuries per 1000 exposed workers was observed (16).

Work-related injuries result from a complex interplay of multiple risk factors. Exposure to physical, mechanical and chemical hazards and the performance of unsafe practices by workers are the leading causes of workrelated injuries. Similarly, psychosocial factors, work arrangements, socio-demographic characteristic of workers, environmental and social conditions are other potential risk factors $(1,3,11,17-19)$.

Reports from France, U.S and China revealed that men have the highest rates of work-related injuries than women. These studies explained that the difference would be in part by the difference in jobs for the same job category and possible by the difference in the perception of risk and in behavior $(1,11,18,20)$. However, studies conducted in eleven urban industries and textile factory in Addis Ababa reported that gender has no association with the prevalence of work-related injuries $(14,15)$.

Work-related injuries among young workers were more common due to lack of experience, lack of knowledge and know-how than in other subjects. Furthermore, many workers begin working at an early age and often without safety training $(14,15,18)$. Low education status, low monthly salary, low working experience (5 years or less) in present job, lack of health and safety training, sleep disorders, job category and alcoholic drink consumption were common risk factor for work-related injuries (1,3$15,17,18,21)$.

Data regarding the status on the disaggregated magnitude and factors affecting work-related injury are lacking for small and medium scale industries in Ethiopia. There are contrasting and contradicting debate concerning the health, safety and welfare of people working in smallscale industries. Some studies suggested that small-scale industries were more dangerous to work in than that of medium industries $(6,7,22)$. This study attempted to contribute in the assessment of the magnitude and factors related to work injuries among small and medium-scale industrial workers in North Gondar, Amhara Regional State.

\section{Methods}

A comparative cross-sectional study design was undertaken in Gondar Wereda to assess and compare the prevalence of work-related injuries and other related factors with injury occurring among small and mediumscale industrial workers from November to December, 2004. The City of Gondar, found in North Gondar Zone, is located 745 kilometers far from Addis Ababa. The Zone is structured into 16 Weredas, 60 urban and 683 rural Kebeles. The study area, Gondar Wereda, was purposely selected for the fact that more than $80 \%$ of the source population is located. It is assumed that this Wereda better represents the zone and in addition logistics convenience was considered for its selection. Gondar Wereda at the time of the study had a total of 140 small and 11 medium scale industries with a total of 566 and 872 employees, respectively $(23,24)$.

All employees working in small and medium scale industries were source population while the factries they were employed were study units. Employees who were only directly engaged in the production process in the selected industries irrespective of sex and age were included in the study as they are more exposed to injuries.

EPI INFO version 6.04 statistical software was used to calculate sample size. Assumed work-related injuries prevalence rate of $50 \%\left(\mathrm{P}_{1}\right)$ and $40 \%\left(\mathrm{P}_{2}\right)$ among small and medium scale industrial workers in order to pick a $10 \%$ significant difference between the prevalence rates were used for a sample size calculation using a two proportion sample size equation designed for a comparative cross-sectional study. Assumptions were also made a $5 \%$ level of significance, a power of $80 \%$, allocation ratio of small to medium-scale industrial workers $\left(n_{1}: n_{2}\right)$ of $1: 2$ and none response rate of $5 \%$. The calculated sample size was 321 participants for small and 641 participants for medium scale industries.

Stratified random sampling technique was applied to get the desired sampling units. For the purpose of this study, the selected industries were stratified into two categories, namely small and medium scale industries. All fifty-two small and all eleven medium-scale industries found in Gondar Wereda at the time of investigation were included in the study. The required sample sizes for each 
stratum of industries were allocated using probability proportional to size. Sampling frame consisted of all workers in production sites were obtained from respective undertakings and simple random sampling technique was administered to identify the study subjects.

The data was collected in the period between November to December, 2004. Pre-tested and a standardized structured questionnaire was administered for data collection. It was prepared in English and translated to Amharic and then back to English to verify the consistency and content of translation. Physical examination was done on injured workers to identify the part of body affected and verify type of injury during the study period, one year prior to data collection. Record review was used to identify deaths occurred as result of work-related injuries. Variables included were sociodemographic, injury characteristics, work environment and behavioral factors of the work force.

Twelve data collectors were recruited from second year degree programme environmental health students who had occupational health and safety course prior to the study. Supervisors were two nurses who had exposures in data collection. All data collectors and supervisors were from Gondar University.

The quality of data was ensured through the training of data collectors and supervisors by principal investigator on the study for 3 days. Local authorities of the study area, and factory managements were formally contacted and informed about the purpose of the study. Checking the completeness, accuracy, and uniformity of the collected data was made at each day of data collection. Data entry, cleaning, and analysis were made using EPIINFO Version 6.04 statistical software. Descriptive statistics such as frequency distribution, mean, percentages, p-values of less than 0, 05 and odds ratio for statistical significant tests were employed for the analysis. Forward stepwise binary logistic regression analysis using SPSS software package version 11.0 was carried out to assess the relative importance of the explanatory variables on the dependent variable. To avoid an excessive number of variables and unstable estimates in the subsequent model, only variables reached a p-value less than 0.3 were kept in the subsequent analyses.

Privacy and confidentiality of respondents' data was maintained in the study. Injuries that were observed at the time of data collection were reported to the factory health management for immediate intervention.

\section{Operational definitions}

- Medium scale industry: any industry that uses power driven machine and employ more than 10 workers (24).
- Small-scale industry: any industry that uses power driven machine and employ less than 10 workers (23).

- Severity of injury: characterized by death, hospitalization more than 24 hours and absence from work over three days in the last one year $(25,26)$.

- Work-related injury: a condition sustained by a worker in connection with the performance of his or her work (27).

\section{Results}

Socio-demographic characteristics of the respondents: A total of 321 and 641 workers from small and mediumscale industries, respectively, were covered by the study. The over inclusions were seven hundred fifty four (78.4\%) males and 208 (22\%) females with a sex ratio of 3.7:1, respectively. The mean (SD) age for the small and medium-scale industrial workers were 29.8 (8.9), respectively. The overall mean age (SD) was 28.5 (9.7) years, ranging from 14 to 69 years. About sixty six percent of the respondents in both industries were young in the age group 14-29 years. About 161 (50.2\%) and 295 (46\%) of the small and medium-scale industry respondents have attended secondary schooling, respectively. Sex, mean age, marital status, monthly income, and working experience were different for both types of industries $(\mathrm{p}<0.05)$ while religion and educational status did not show statistically significant differences. Young male workers with working experience of $<5$ years were the characteristics of smallscale industry while better payment and longer work experience were common features to medium-scale industry (Table 1).

Characteristics of work-related injuries: A total of 322 workers (33.5\%) reported that they had experienced work-related injury in the previous one year. Out of the total work-related injuries 114 (35.5\%) and 208 (32.4\%) appeared in small and medium-scale industrial workers, respectively. There was no difference in the prevalence of work-related injury between small and medium-scale industrial workers $\left(\mathrm{X}^{2}=0.90, \mathrm{P}>0.05\right)$. A total of 158 (49.1\%) of the injured respondents faced more than one injury and 115 (12\%) respondents had experienced workrelated injuries for a two weeks period prior to data collection. The number of injuries per worker, frequency of injury for the two weeks and one-year recall time were significant by the type of industry. A frequency of more than once injury per worker was commonly observed among workers in medium scale industry while the prevalence of injury for the two week recall time was more among medium-scale industry workers $(\mathrm{p}<0.05)$ (Table 2). 
Table 1: Selected Socio-demographic characteristics of the respondents by type of industry, Gondar Woreda, Nov. - Dec. 2004.

\begin{tabular}{|c|c|c|c|c|}
\hline Background Variables & $\begin{array}{l}\text { SSI }(n=321) \\
N(\%)\end{array}$ & $\begin{array}{l}\text { MSI (n=641) } \\
\text { N (\%) }\end{array}$ & $\begin{array}{l}\text { Total }(n=962) \\
N(\%)\end{array}$ & $\mathrm{X}^{2}$ \\
\hline \multicolumn{5}{|l|}{ Sex } \\
\hline Female & $18(5.6)$ & $190(29.6)$ & $208(21.6)$ & \multirow[t]{2}{*}{$72.90^{*}$} \\
\hline Male & $303(94.4)$ & $451(70.4)$ & 754 (78.4) & \\
\hline \multicolumn{5}{|l|}{ Age Group } \\
\hline $14-29$ & $245(76.3)$ & 391 (61.9) & $636(66.1)$ & \multirow[t]{4}{*}{$22.78^{*}$} \\
\hline $30-44$ & $53(16.5)$ & $184(28.7)$ & $237(24.6)$ & \\
\hline $45+$ & $23(7.2)$ & $66(10.3)$ & $89(9.3)$ & \\
\hline Mean (SD) & $25.7 \pm 9.9$ & $29.8 \pm 9$ & $28.5 \pm 9.7$ & \\
\hline \multicolumn{5}{|l|}{ Educational level } \\
\hline Illiterate & $24(7.5)$ & $34(5.3)$ & $58(6.0)$ & \multirow[t]{5}{*}{6.61} \\
\hline Can read and write & $12(3.7)$ & 31 (4.8) & $43(4.5)$ & \\
\hline Primary & $70(21.8)$ & $181(28.2)$ & $251(26.1)$ & \\
\hline Secondary & $161(50.2)$ & $295(46.0)$ & $456(47.4)$ & \\
\hline $12+$ & $54(16.8)$ & $100(15.6)$ & $154(16.0)$ & \\
\hline \multicolumn{5}{|l|}{ Monthly salary (in Birr) } \\
\hline$\leq 200$ & $193(60.1)$ & $176(27.4)$ & $369(38.4)$ & \multirow[t]{3}{*}{$97.62^{*}$} \\
\hline $201-600$ & $100(31.2)$ & 339 (52.9) & $439(45.6)$ & \\
\hline $600+$ & $28(8.7)$ & $126(19.7)$ & $154(16.0)$ & \\
\hline \multicolumn{5}{|c|}{ Work experience (in years) } \\
\hline$\leq 5$ & $241(75.1)$ & $396(61.8)$ & $637(66.2)$ & \multirow[t]{2}{*}{$16.91^{*}$} \\
\hline $6+$ & $80(24.9)$ & $245(38.2)$ & $325(33.8)$ & \\
\hline
\end{tabular}

Note: $\mathrm{SSI}=$ small scale industries; $\mathrm{MSI}=$ Medium scale industries

* indicates significant differences

Severity of work-related injuries: Of the total 322 injured respondents within a year 55 (17.1\%) were hospitalized, which accounts $40 \%$ hospitalization for more than 24 hours. One hundred and three (53.9\%) were absent from work for more than 4 days. As a result of 322 work-related injuries about 191 working days were lost and two deaths were reported because of work related injuries in the sampled industries in the last 12 months. However, severity of work-related injury was not associated with the type of industry.
Work environment and behavioral characteristics of respondents by type of industry: Sixty four (19.9\%) of small and 433 (67.6\%) of medium-scale workers reported that they worked more than 48 hours per week. Hours worked per week was significantly associated with the type of factory $(\mathrm{P}<0.05)$. More hours per week was spent among medium-scale industrial workers $(\mathrm{p}<0.05)$. Out of the total respondents $42 \%$ of small and $39.9 \%$ of medium-scale industrial workers reported that their workplaces were not supervised regularly.

Table 2: Distribution of work-related injury in the last 12 months among respondents by type of industry, Gondar Woreda, Nov.-Dec. 2004

\begin{tabular}{|c|c|c|c|c|}
\hline Variables & $\begin{array}{l}\text { SSI (n=321) } \\
N(\%)\end{array}$ & $\begin{array}{l}\text { MSI (n=641) } \\
\text { N (\%) }\end{array}$ & $\begin{array}{l}\text { Total }(n=962) \\
N(\%)\end{array}$ & $\mathrm{X}^{2}$ \\
\hline \multicolumn{5}{|c|}{ Work-related injuries in the last 12 months } \\
\hline Yes & $114(35.5)$ & $208(32.4)$ & $322(33.5)$ & 0.90 \\
\hline No & $207(64.5)$ & $433(67.6)$ & $640(66.5)$ & \\
\hline \multicolumn{5}{|c|}{ Number of occurrence in the last 12 months } \\
\hline Once & $67(55.8)$ & $97(35.5)$ & $164(50.9)$ & $4.34^{*}$ \\
\hline More than once & $47(41.2)$ & $111(64.5)$ & $158(49.1)$ & \\
\hline \multicolumn{5}{|c|}{ Work-related injuries in the last 2 weeks } \\
\hline Yes & $28(8.7)$ & $87(13.6)$ & $115(12.0)$ & $4.78^{*}$ \\
\hline No & $293(91.3)$ & $554(86.4)$ & $847(88.0)$ & \\
\hline \multicolumn{5}{|c|}{ Number of occurrence in the last 2 weeks } \\
\hline Once & $22(78.6)$ & $41(47.1)$ & $63(54.8)$ & $8.46^{*}$ \\
\hline More than once & $6(21.4)$ & 46 (52.9) & $52(45.2)$ & \\
\hline
\end{tabular}

Note: $\mathrm{SSI}=$ Small scale industries; $\mathrm{MSI}=$ Medium scale industries; * indicates significant differences

About ten percent of small and twenty three percent of medium-scale industrial workers reported that they had sleep disorder at their workplace. Sleep disorder was significantly associated with the type of industry
( $<<0.05)$. The majority (82.5\%) of small and (73.9\%) of medium-scale industrial workers reported that they were satisfied by their current job $(\mathrm{p}<0.05)$. Personal handling of protective devises was also significantly associated 
with the type of factory $(\mathrm{p}<0.05)$. The bivariate analysis indicated that more hours per week and sleeping disorders were statistically significant among mediumscale industrial workers while job satisfaction and proper handling of personal protective devises were more significant characteristics of small-scale industrial workers (Table 3).

Table 3: Reported work environment and behavioral characteristics of respondents, Gondar Woreda, Nov. - Dec. 2004.

\begin{tabular}{|c|c|c|c|c|}
\hline Variables & $\begin{array}{l}\text { SSI }(n=321) \\
N(\%)\end{array}$ & $\begin{array}{l}\text { MSI (n=641) } \\
\text { N (\%) }\end{array}$ & $\begin{array}{l}\text { Total }(n=962) \\
\text { N (\%) }\end{array}$ & $\mathrm{X}^{2}$ \\
\hline \multicolumn{5}{|c|}{ Hours worked per week } \\
\hline$\leq 48$ & $257(80.1)$ & $208(32.4)$ & $465(48.3)$ & \\
\hline $48+$ & $64(19.9)$ & $433(67.6)$ & $497(51.7)$ & $194^{*}$ \\
\hline \multicolumn{5}{|c|}{ Workplace supervision } \\
\hline Yes & $135(42.1)$ & $256(39.9)$ & $391(40.6)$ & 0.40 \\
\hline No & $186(57.9)$ & $385(60.1)$ & $571(59.4)$ & \\
\hline \multicolumn{5}{|c|}{ Health and safety training } \\
\hline Yes & $153(47.7)$ & $266(41.5)$ & $419(43.6)$ & 3.31 \\
\hline No & $168(52.3)$ & $375(58.5)$ & $543(56.4)$ & \\
\hline \multicolumn{5}{|c|}{ Sleeping disorder } \\
\hline Yes & $31(9.7)$ & $144(22.5)$ & $175(18.2)$ & $23.58^{*}$ \\
\hline No & $290(90.3)$ & $497(77.5)$ & $787(81.8)$ & \\
\hline \multicolumn{5}{|c|}{ Job satisfaction } \\
\hline Yes & $265(82.6)$ & $474(73.9)$ & 739 (76.8) & $8.90^{*}$ \\
\hline No & $56(17.4)$ & $167(26.1)$ & $223(23.2)$ & \\
\hline \multicolumn{5}{|l|}{ Use PPE } \\
\hline Yes & $244(76.0)$ & $345(53.8)$ & $589(61.2)$ & $44.37^{*}$ \\
\hline No & $77(24.0)$ & $296(46.2)$ & $373(38.8)$ & \\
\hline
\end{tabular}

Note: $\mathrm{SSI}=$ Small scale industries; MSI=Medium scale industries; * indicates significant differences; PPE is personal protective devices

Determinants of work-related injuries: Sociodemographic, working environment and behavioral determinants in relation to injury were analyzed by bivariate and multi-variate analyses using logistics regression model. Age at the time of interview, job categories and work experience were identified as the major socio-demographic determinants of work-related injury for both industrial workers. Being young workers, mechanic and welder by job categories and few work experiences were shown to positively impact injury with adjusted odds ratio (AOR) and 95\% CI, respectively [A0R=1.41(1.03,1.93], [AOR=2.09 (1.31,3.33)], $[\mathrm{AOR}=3.23(1.98,5.28)], \quad[\mathrm{AOR}=1.53(1.12,2.08)] . \quad \mathrm{Sex}$, educational level and monthly salary of workers did not show any association with injury (Table 4).

Table 4: Associations of socio-demographic factors of respondents with prevalence of work-related injuries by type of ndustry, Gondar Woreda, Nov.-Dec. 2004 ( $\mathrm{N}=962)$

\begin{tabular}{|c|c|c|c|c|c|c|c|c|}
\hline \multirow{3}{*}{ Variables } & \multicolumn{6}{|c|}{ Injured } & \multirow[b]{3}{*}{ COR, $(95 \% \mathrm{Cl})$} & \multirow{3}{*}{ AOR, (95\%Cl) } \\
\hline & \multicolumn{2}{|c|}{ SSI (n=321) } & \multicolumn{2}{|c|}{ MSI (n=641) } & \multicolumn{2}{|c|}{ Total $(n=962)$} & & \\
\hline & Yes & No & Yes & No & Yes & No & & \\
\hline \multicolumn{9}{|l|}{ Sex } \\
\hline Female & 3 & 15 & 55 & 135 & 58 & 150 & $0.72(0.51,1.00)$ & \\
\hline Male & 111 & 192 & 153 & 298 & 264 & 490 & 1.00 & \\
\hline \multicolumn{9}{|l|}{ Age group } \\
\hline$<30$ & 86 & 159 & 143 & 248 & 229 & 407 & $1.41(1.05,1.88)$ & $1.41(1.03,1.93)^{\star}$ \\
\hline$\geq 30$ & 28 & 48 & 65 & 15 & 93 & 233 & 1.00 & 1.00 \\
\hline \multicolumn{9}{|l|}{ Educational level } \\
\hline Primary & 37 & 41 & 68 & 113 & 105 & 154 & $0.86(0.57,1.30)$ & \\
\hline Secondary & 58 & 63 & 89 & 206 & 147 & 269 & $0.81(0.54,1.21)$ & \\
\hline $12+$ & 19 & 35 & 38 & 62 & 57 & 97 & 1.00 & \\
\hline \multicolumn{9}{|l|}{ Job category } \\
\hline Daily laborer & 9 & 28 & 68 & 113 & 77 & 141 & $1.67(1.09,2.55)$ & $1.37(0.88,2.13)$ \\
\hline Mechanic & 33 & 56 & 20 & 30 & 53 & 86 & $1.88(1.17,3.03)$ & $2.09(1.31,3.33)^{\star}$ \\
\hline Machine operator & 37 & 3 & 77 & 168 & 114 & 171 & $1.39(0.92,2.11)$ & $1.11(0.73,1.68)$ \\
\hline Welder & 48 & 44 & 5 & 14 & 53 & 58 & $2.79(1.69,4.61)$ & $.23(1.98,5.28)^{\star}$ \\
\hline Others & 21 & 72 & 38 & 108 & 59 & 180 & 1.00 & 1.00 \\
\hline \multicolumn{9}{|l|}{ Work experience } \\
\hline$\geq 5$ years & 85 & 156 & 144 & 252 & 229 & 408 & $1.53(1.14,2.05)$ & $1.53(1.12,2.08)^{*}$ \\
\hline $6+$ years & 29 & 51 & 64 & 181 & 93 & 232 & 1.00 & 1.00 \\
\hline
\end{tabular}

AOR: Adjusted for environment and behavioral factors (hours 229 worked per week, workplace supervision, sleep disorder, job satisfaction): *indicates significant association 
From the workplace variables, hours worked per week, presence of workplace supervision, health and safety training showed significant association with the prevalence of work-related injuries. Engagement in less than or equal to 48 working hours per week, workplace supervision and having a training in health and safety looked to be protective factors for the occurrence of injury with the corresponding [AOR $=0.68,95 \% \mathrm{CI}$ : $(0.49,0.94)], \quad[\mathrm{AOR}=0.61, \quad 95 \% \mathrm{CI}:(0.45,0.83)]$, [AOR=0.60, 95\%CI:(0.46,0.79)], respectively (Table 5).

Table 5: Associations of environmental factors of respondents with prevalence of work related injuries, Gondar Woreda, Nov.-Dec. 2004 ( $\mathrm{n}=962)$

\begin{tabular}{|c|c|c|c|c|c|c|c|c|}
\hline \multirow{3}{*}{ Variables } & \multicolumn{6}{|c|}{ Injured } & \multirow[b]{3}{*}{ COR, $(95 \% \mathrm{Cl})$} & \multirow[b]{3}{*}{ AOR, $(95 \% \mathrm{Cl})$} \\
\hline & \multicolumn{2}{|c|}{ SSI (n=321) } & \multicolumn{2}{|c|}{ MSI (n=641) } & \multicolumn{2}{|c|}{ Total $(n=962)$} & & \\
\hline & Yes & No & Yes & No & Yes & No & & \\
\hline \multicolumn{9}{|c|}{ Hours worked per week } \\
\hline$\leq 48$ & 34 & 63 & 12 & 46 & 46 & 109 & $0.57(0.42-0.75)$ & $0.68(0.49,0.94)^{\star}$ \\
\hline$>48$ & 80 & 144 & 196 & 387 & 276 & 531 & 1.00 & 1.00 \\
\hline \multicolumn{9}{|c|}{ Workplace supervision } \\
\hline Yes & 43 & 92 & 59 & 194 & 102 & 286 & $0.56(0.42-0.75)$ & $0.61(0.45,0.83)^{\star}$ \\
\hline No & 71 & 115 & 149 & 239 & 220 & 351 & 1.00 & 1.00 \\
\hline \multicolumn{9}{|c|}{$\begin{array}{l}\text { Health and safety } \\
\text { training }\end{array}$} \\
\hline Yes & 43 & 110 & 71 & 195 & 114 & 305 & $0.60(0.45-0.79)$ & \\
\hline No & 71 & 207 & 137 & 238 & 208 & 445 & 1.00 & \\
\hline
\end{tabular}

AOR: Adjusted for socio-demographic and behavioral factors (age, job category, work experience, monthly salary, sleep disorder, job satisfaction).; * indicates significant association

With regard to workers behavior sleep disorder and job satisfaction were positively associated with work related injuries. Respondents who had sleep disorder were more likely to have worker-related injury than their counterparts [AOR=1.49, 95\% CI: (1.04-2.14)]. Workers who had current job satisfaction and regular workplace supervision were less likely to report work (0.59) related injury [AOR=, 95\%CI: $(0.43,0.83)]$ (Table 6$)$.

Table 6: Association of behavioral factors of respondents with prevalence of work related injuries, Gondar Woreda, Nov.-Dec. 2004 ( $n=962)$

\begin{tabular}{|c|c|c|c|c|c|c|c|c|}
\hline \multirow{3}{*}{ Variables } & \multicolumn{6}{|c|}{ Injured } & \multirow[b]{3}{*}{ COR, $(95 \% \mathrm{Cl})$} & \multirow[b]{3}{*}{ AOR, $(95 \% \mathrm{Cl})$} \\
\hline & \multicolumn{2}{|c|}{ SSI (n=321) } & \multicolumn{2}{|c|}{ MSI (n=641) } & \multicolumn{2}{|c|}{ Total $(n=962)$} & & \\
\hline & Yes & No & Yes & No & Yes & No & & \\
\hline \multicolumn{9}{|c|}{ Sleeping disorder } \\
\hline Yes & 10 & 21 & 69 & 75 & 79 & 96 & $1.84(1.32,2.57)$ & $1.49(1.04,2.14)$ \\
\hline No & 104 & 186 & 139 & 358 & 243 & 544 & 1.00 & 1.00 \\
\hline \multicolumn{9}{|c|}{ Job satisfaction } \\
\hline Yes & 94 & 171 & 126 & 348 & 220 & 519 & $0.50(0.37,0.68)$ & $0.59(0.43,0.83)$ \\
\hline No & 20 & 36 & 82 & 85 & 102 & 121 & 1.00 & 1.00 \\
\hline \multicolumn{9}{|l|}{ Use PPE } \\
\hline Yes & 43 & 92 & 59 & 197 & 102 & 289 & $0.85(0.65,1.12)$ & \\
\hline No & 71 & 115 & 149 & 239 & 220 & 354 & 1.00 & \\
\hline
\end{tabular}

AOR: Adjusted for socio-demographic and behavioral factors (age, job category, work experience, monthly salary, sleep disorder, job satisfaction).; * indicates significant association

Multivariate Logistic regression analysis: Stepwise forward binary logistic regression analysis was carried out by taking a conceptual framework into account to assess the relative effect of the explanatory variables (socio-economic, environmental, and behavioral factors) on the dependent variable. To avoid an excessive numbers of variables and unstable estimates in the subsequent model, only variables reached a p-value less than 0.3 were kept in the subsequent analyses.

The overall effect of the selected socio-demographic variables (Table 4) on the occurrence of work-related injury was assessed in the first step. In the second step of the analysis, the work environment variables (Table 5) were added, and their effect was assessed in the presence of the socio-demographic variables. Behavioral factors as indicated in Table 6 were entered in the third step. In this step, the effect of the selected behavioral factors was assessed in the presence of both socio-economic and workplace factors. Table 7 presents the sociodemographic, workplace and behavioral variables which remained in each step of the logistics regression analysis.

Among above-mentioned socio-demographic explanatory variables computed in the first step of the analysis, job categories like mechanic and welders significantly resisted in the final step while age at interview was remained to be statistically significant in the second step of analysis.

Workers whose age below 30 years had more than 1.4 times higher odds of having work-related injury than 
workers whose age 30 years and above [AOR:1.41,95\% CI: $(1.03,1.93)]$ in the second step of the analysis.
However, its significance disappeared in the first and third level of analysis.

Table 7: Summary of the stepwise logistic regression analysis of the relative effect of socio demographic, work environment and behavioral factors on the prevalence of work related injuries, Gondar Woreda, Nov.-Dec. 2004

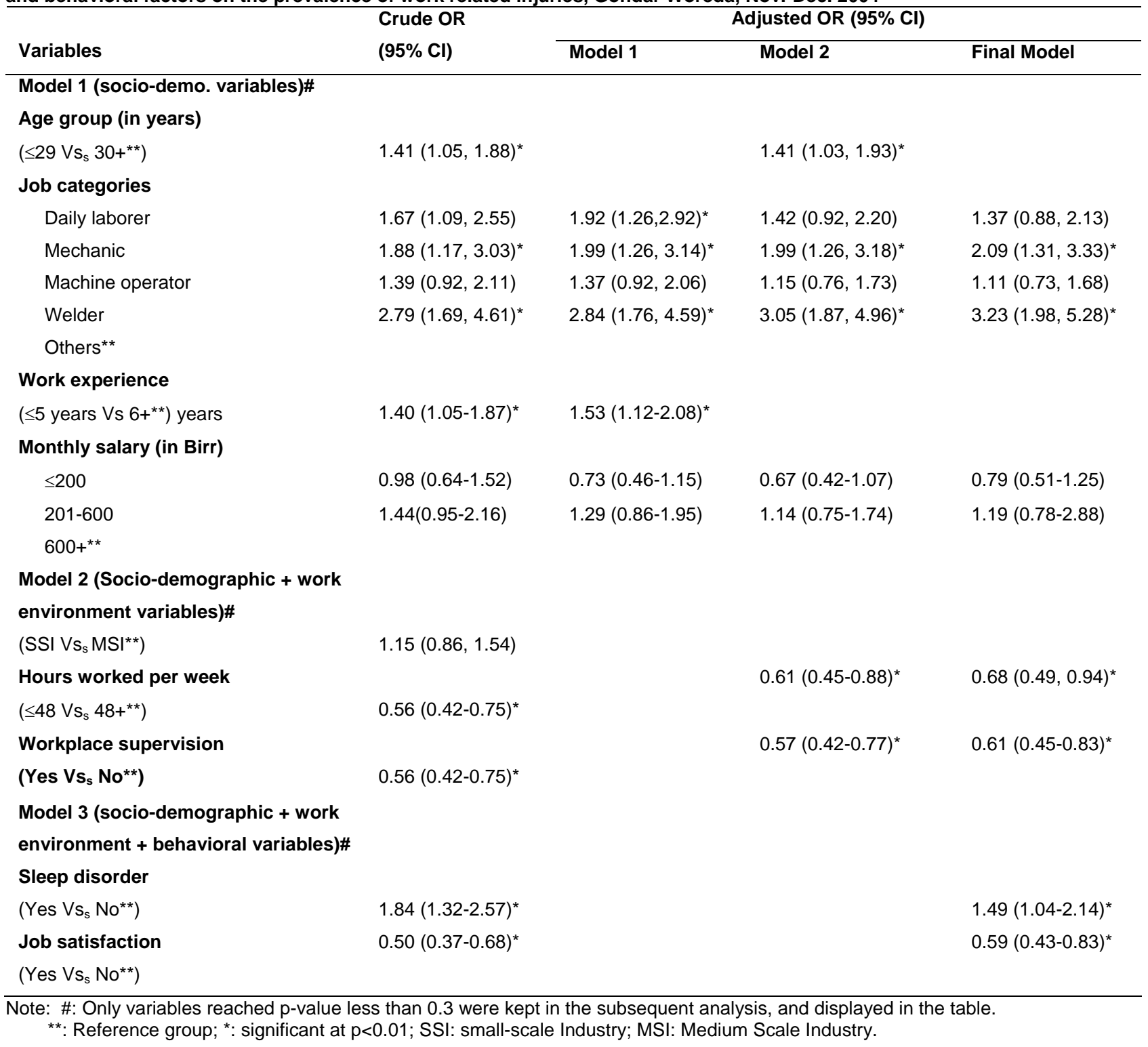

According to this study welders continued more than three times higher odds of having work-related injuries than the other job categories [AOR:3.23, 95\% CI: $(1.98,5.28)]$. The odds of having work-related injuries in workers who had working experience of 5 years or below were 1.5 times higher than the odds of workers who had served 6 years and above at the time of survey [AOR=1.53, 95\%CI:(1.12,2.08)].

From working environment variables analyzed in the second step, hours for work per week and supervision of workplace found to be significant in the final model. Respondents who worked 48 and below hours per week and those who supervised regularly at the time of the survey were less likely to experience work-related injury than those who were worked more than 48 hours per week and not supervised [AOR: 0.68, 95\% CI: (0.49,0.94) and AOR: 0.61,95\% CI: (0.45, 0.83)], respectively. The difference in the prevalence of workrelated injuries was assessed among small and mediumscale industrial workers. In this study, no statistically significant difference was observed between the two groups [AOR:1.14, 95\% CI: $(0.78,1.67)]$.

Sleep disorder and job satisfaction showed statistically significant association in the final step of analysis [AOR: 1.49, 95\% CI: $(1.04,2.14)$ and (AOR: 0.59, 95\%CI: $(0.43,0.83)]$, respectively (Table7). 


\section{Discussion}

This institution-based cross-sectional comparative study attempted to assess the prevalence of work-related injuries in the last 12 months among small and mediumscale industrial workers in North Gondar Zone, Amhara Regional State.

In the study, the overall annual prevalence rate of workrelated injury was 335 injuries per 1000 exposed workers. The two-week period incidence rate, on the other hand, was 120 injuries per 1000 exposed workers. In our study the annual prevalence of injury was markedly greater than that of large-scale industries elsewhere (14). It was also comparatively greater than in similar studies done (11-13), in Norwegian (9). Such variations in the prevalence of work-related injuries are linked to level of development, status of workforce in a given country, and strengths of occupational health services. Discussions with factory management indicated that the weekly progressing occupational health programs among studied units in our study.

In this study, a large discrepancy was observed between the annual prevalence and two week incidence rates. This discrepancy might be explained by recall bias as some workers forget some minor injuries emerged into them in one-year period and better remembered those injuries that they sustained in two weeks recall period. There could be also seasonal variations in the occurrence of work-related injuries in sampled industries. The seasons may result in limited supply of raw materials to some industries that may impact the activity of factories and needed number of workers which could engage in actively as a work force. This may lead to low frequency of injury due to less interaction in the workplaces. On the other hand, seasons may result in increased production, which may also lead to increased employment. This may result in an increased frequency of injury due to increased industrial activity.

The results of this survey indicated that statistically significance difference was not observed in the annual prevalence of work-related injuries between small and medium scale industrial workers. This might be explained, to some extent, by lack of difference in working conditions, working environment and status of workforce in both types of industries. Recall bias could also potentially affect the variations in the outcome of injury. Studies, to the contrary of our findings, have shown that small-scale industrial workers are at greater risk of work-related injuries because of low education and literacy rates, inadequate training, unfamiliarity with work processes and exposures $(6,7,22)$.

The non-significant difference in the annual rate of injury by industry was not consistent with the two weeks incidence of injury and the number of injuries per worker. The high rate of two weekly injury rates and the occurrence of more frequent injuries among workers in medium scale industry than that of in small-scale industry can be explained by hazards due to the use of unprotected machines, less work supervision, dissatisfaction with job and sleeping disorders caused by extended working hours per week. One should not, however, underestimate the possible role of recall and social desirability bias in the assessment of injury for the two weeks period. Worker's regular work supervisions that could provide advices in the protection of worker's health and use of personal protective devices and conditions in job satisfaction have made also differences in injury rates by type of industry.

The assessment of severity of injury by rate of hospitalization and working days lost looked to be high, given limited sources in the study units. The severity of injury was not associated with type of industry in this study. Work-related injuries are assumed to be preventable with the provision of occupational health programs in workplaces. The magnitude and depth of injury are likely to bring significant changes in productivity and affect expenses through medical and compensation costs. Study done in Lebanon showed that the cost of work related injuries sharply increased with the severity of injury. This study has also reported that three $(0.1 \%)$ of deaths related to work injuries consumed $3.8 \%$ of the overall costs. Furthermore, injuries that resulted in the hospitalization were 12 times coasty as much per injury as those did not (26).

Regarding age groups, a higher risk was found in subjects aged less than 30 years $(\mathrm{OR}=1.41,95 \% \mathrm{CI}$ : (1.03-1.93). Similar observation was also reported by other investigators $(1,3,11,14,15,17,18,28-31)$. The findings indicated that the reasons for higher workrelated injuries amongst young people include lack of information, lack of training, lack of supervision, lack of experience on the job, lack of knowledge and skill. Many workers begin work at an early age and often without safety training.

Job categories of mechanic and welding experienced more work related injuries than other workers. This could demonstrate that job category proxy factors for occupational hazards and the difference in the perception of risk and behavior $(17,32)$. These job categories were believed to be actively engaged in work that required the application of moving parts of machines that predispose to a risk of injury. The perception of risk in different job categories could also be a factor to injuries. This finding highlighted that improvement in working conditions and training should be carried out for all workers, but especially for workers with higher risk, who are mechanics and welders.

The present study showed that 5 years or less in the present job played a role in work-related injuries. Similar 
findings were observed in different studies $(1,3,17)$. These studies showed that lack of experience influences the interaction between the person and other workers, knowledge of machines and tools in use and their defects, and awareness of surrounding hazards.

One potentially predictor of work-related injury is work time- that is, the length of time worked per shift, week or indeed any other time. In this study, workers who worked 48 hours and below per week were less likely to sustain work related injuries than their counter parts. This difference could partly explained as fatigue associated with long hours of work that may increase the likelihood of work related injuries, and that exceptionally long hours may also result in injuries associated with breaching physical endurance limits. Long work time impair rest and sleep (19).

The occurrence of work-related injury was significantly related to sleep disorder. This could explain that sleep disorder affect the ability to maintain wakefulness, concentration, ability in assessing or watching the work environment and working conditions and performing duties and health status. Most occupational health and safety studies conducted in developing and developed countries strongly agree with this report $(1,17,18,34-36)$.

An increasing number of studies have considered job satisfaction and regular supervision of workplace as pervasive and influential factors in the occurrence of work-elated injuries in the work environment $(11,37,38)$. The result of this study revealed that risk of work-related injury decreased with job satisfaction and workplace supervision.

This study has the following limitations. The study was a one-year cross-sectional study. The possibility of recall biases resulting in under or over reporting and misreporting of events was likely. There could be also seasonal variations in occurrence of work injuries. The seasons may result in either adequate or limited supply of raw materials that could possibly affect the outcome of injury.

\section{Conclusion and recommendations}

The results of this study found high rates of work-related injuries among small and medium-scale industrial workers in one-year period prior to this study. The workrelated injury rate was not different by type of industries. The two weeks injury rate and the number of injuries per worker differed by type of industry. The depth of injures as measured by rate of hospitalization and work days lost was also relatively high, which is likely to impact productivity.

Consistent with other studies, workers who were young, less experienced, job categories of mechanic and welding, and sleep disorder had significantly higher risks of work-related injury. There is a growing body of evidence suggesting that there are social and demographic gradients in the occurrence of work-related injuries. Working 48 hours or below per week, job satisfaction and workplace supervision significantly decreased the occurrence of injuries.

Considering the large contribution to national gross domestic product (GDP) made by small and mediumscale industries, and that there is a great needs of investment in Ethiopia, effective and sustainable preventive measures concerning health and safety training, regular workplace supervision and establishment of active and functional occupational health and safety program are essentials to safeguard the health and safety condition of workforce in small and medium scale industries.

\section{Acknowledgment}

Authors are grateful to Addis Ababa University and Gondar University for the generosity in financial and logistics support. Our heart-felt thanks are also due to North Gondar Zonal Administration, each industry management, and study participants for the full and well done cooperation shown during data collection.

\section{References}

1. Ashi Bhattachersee. Relationships of job and some individual characteristics to occupational injuries in employed people. A community-based study. Occup Health 2003;45:382-391.

2. Ahn Y-S, Bena J F, Bailer A J. Comparison of unintentional fatal occupational injuries in the Republic of Korea and the United States. Injury prevention 2004;10:199-205.

3. Nearkasen, etal. Correlates of occupational injuries for various jobs in railway workers. J Occup Health 2004;46:272-280.

4. WHO. Occupational health program of WHO Headquarters, Geneva, Switzerland. The Global Occupational Health Network 2003; pp.1-2

5. WHO/ILO. Occupational health and safety in Africa. Meeting report. World Health Organization with input of WHO/ILO Joint Effort Taskforce 2001; pp.5-6.

6. Tetsuya Mizoue. Analysis of Japanese occupational health services for small and medium scale enterprises in comparison with the Finnish system. J.Occup Health 1999; pp.115-120.

7. Kebede Faris. Survey of occupational safety and sanitary condition in small-scale enterprises in Jimma southwestern Ethiopia. Ethiop J Health Dev. 1998;12:183-190.

8. Park H., etal. Evaluation of occupational health service systems in small and medium-sized industries in Korea. Int Arch Occup Environ Health 2001;74:68-78. 
9. Bull N, T.Riise and B.E Moen. Work-related injuries and occupational health and safety factors in small enterprises-Prospective study. Occup. Med 2002;52:70-74.

10. Somkiat Siriruttanapruk and Pensri Anantagulnathi. Occupational health and safety situation and research priority in Thailand. Industrial Health 2004;42:135140.

11. Dembe AE, Erickson JB, Delbos R. Predictors of work-related injuries and illness: National survey findings Occup Environ Hyg. 2004;8:542-550.

12. Loewenson RH. Health impact of occupational risks in informal sectors in Zimbabwe. In $\mathrm{J}$ Occup Environ Health 1998;4:264-274.

13. Afamdi O.Ezenwa. A study of fatal injuries in Nigerian factories. Occup. Med 2001;51:458-489.

14. Aberra Fulle.Injuries in urban factories of Ketena one, Addis Ababa. Masters Thesis, Addis Ababa University 1988.

15. Elias Senbeto. The incidence of injuries and their determinants in Akaki textile factory, Addis Ababa. Masters Thesis, Addis Ababa University 1991

16. Ministry of Health Department of Environmental Health .Occupational health and safety assessment in selected factories in Ethiopia 1996; PP.1-28 (unpublished).

17. Chau N, etal. Relationships between some individual characteristics and occupational accidents in the construction industry. Occup Health 2002;44:131139.

18. Liv XR, Zhonghu Lao, Dong Wei, Sheng Zhiye, Bing Za Zhi. Relationship Occupational injuries with social and economic factors 2004;22:86-89.

19. Roger Wilkins. Do long working hours lead to more workplace Injuries? Evidence from Australian industry-level panel data. Melbourne institute of applied economic and social research. The University of Melbourne 2004; pp.3-5.

20. Smith PM , Mustrad CA. Examining the association between physical work demands and work injuries between men and women. Occup Environ med 2004;61:750-756.

21. Bill Graves. Census of fatal occupational injuries in Kansas: Kansas Department of Health and Environment 2000; pp.1-15.

22. Daniel. Levels and Trends in Workplace injury: rates of injury within small and large manufacturing work places. Health and safety commission National Statistics 2001; pp.1-2.

23. Central Statistical Authority. Report on small scale manufacturing industries survey. Addis Ababa Sept. 2002.

24. Central Statistical Authority. Report on large and medium scale manufacturing and electricity industries survey. Statistical Bulletin No.281, Addis Ababa Sept. 2002.
25. Takala J. Introductory Report: Decent work-safe work. XVI ${ }^{\text {th }}$, World Congress on safety and health at work 2002:4-10.

26. Rim Fayad. Cost of work-related injuries in injured workers places in Lebanon. Bulletin of the World Health Organization 2003; 81:509-516.

27. Ministry of Labor and Social Affairs. Labor proclamation No.377/2003.Federal Negarit Gazeta. No12, Addis Ababa, Ethiopia 2004:2476-2477.

28. R Noe, J Rocha, C Clavel-Arcas, C Aleman, M E Gonzales and C Mock. Occupational injuries identified by emergency department based: injury surveillance system in Nicaragua. Injury prevention 2004;10:227-232.

29. Paul A. Schulte, Carol Merry Stephenson, Andrea H. Okun, John Palassis, and Elyce Biddle. Integrating occupational safety and Health information into vocational and technical educational and other workforce preparation programs. American Journal of Public Health 2005;95:404-411.

30. Jackson L L. Non-fatal occupational injuries and illnesses treated in hospital emergency department in the United States. Injury prevention 2001;7:21-26.

31. Righi E, Gatti G, Marcheselli R, Fantuzzi G, Aggazzotti G. Epidemiology of work related injuries in young people: results survey carried out in Modena (Italy) 2003;15:735-745.

32. Minouk J Schoemaker, Sandhi M Barreto, Anthony J Swerdlow, Craig D Higgins, Robert G Carpenter. Non fatal work-related injuries in a cohort of Brazilian steel workers. Occup Environ Med. 2000;57:555-567.

33. Ulfabers J, N Carter and C Edling. Sleep disorder breathing and occupational accidents. Scand J Work Environ Health 2000;26:237-242.

34. HorneY, Reyner L.Vehicle accidents related to sleep: a review. Occup1999;56:289-294.

35. Snelamed and A oksenberg. Excessive day time sleepiness and risk of occupational injuries in nonshift day time works. J Sleep 2002;25:315-322.

36. Akerstedt T, Fredlund P, Gillberg M, Jansson B. A prospective study on fatal occupational accidentsrelationship to sleeping difficulties and occupational factors. J Sleep Res.2002;11:69-71

37. Chau N .Relationships between certain individual characteristics and occupational injuries for various jobs in the construction industry. Am J Ind Med. 2004;45:84-92.

38. C.-Y. Li, K.-R. Chen, C.-H. Wu, and F.-C. Sung . Job stress and satisfaction in association with non fatal injuries on the job in cross sectional sample of petrochemical workers. Occup Med. 2001;51:50-55. 